\title{
ZnO Nanowires, Nanotubes, and Complex Hierarchical Structures Obtained by Electrochemical Deposition
}

\author{
JAMIL ELIAS, ${ }^{1,2,4}$ JOHANN MICHLER, ${ }^{2}$ LAETITIA PHILIPPE, ${ }^{2}$ \\ MING-YUN LIN, ${ }^{2,3}$ CHRISTOPHE COUTEAU, ${ }^{3}$ GILLES LERONDEL, ${ }^{3}$ \\ and CLAUDE LEVY-CLÉMENT ${ }^{1,5}$
}

1.-CNRS-ICMPE, 2/8 rue Henri Dunant, 94320 Thiais, France. 2.-EMPA Materials Science and Technology, Feuerwerkstrasse 39, 3602 Thun, Switzerland. 3.-ICD/LNIO, CNRS-STMR, Université de Technologie de Troyes, 12 rue Marie Curie, 10010 Troyes, France. 4.-e-mail: jamil.elias@empa.ch. 5.—e-mail: levy-clement@glvt-cnrs.fr

Increasing the aspect ratio of $\mathrm{ZnO}$ nanostructures is one possible strategy to improve their thermoelectric properties. $\mathrm{ZnO}$ nanostructures with onedimensional (1D) and three-dimensional (3D) morphologies were obtained using electrochemical deposition. Adjusting various deposition parameters made it possible to obtain arrays of vertically aligned $\mathrm{ZnO}$ nanowires (NWs) with controlled dimensions, density, and electrical properties. The concentrations of zinc or chloride ions in the solution were found to be key parameters. $\mathrm{ZnO} \mathrm{NWs}$ were transformed into $\mathrm{ZnO}$ nanotubes (NTs), with an increased aspect ratio compared with the NWs, by selectively dissolving the core of the $\mathrm{ZnO} \mathrm{NWs}$ in a concentrated $\mathrm{KCl}$ solution. The aspect ratio was strongly increased when the ZnO NWs were hierarchically organized in a 3D morphology. The synthesis of thin films composed of ordered hollow urchinlike $\mathrm{ZnO} \mathrm{NW}$ structures was performed by combining the electrochemical deposition and polystyrene sphere templating methods. The electronic properties of the urchin-like $\mathrm{ZnO}$ structures were investigated by means of photoluminescence and transmission measurements.

Key words: Zinc oxide, nanowires, nanotubes, urchins, electrochemical deposition, sphere lithography, electrical and emission properties

\section{INTRODUCTION}

$\mathrm{ZnO}$ exists in various nanoscale forms, allowing many device applications. $\mathrm{ZnO}$ nanowires (NWs) exhibit good electrical conductivity, large aspect ratio, and a highly corrugated surface morphology. The combination of good electrical conductivity and corrugated surface morphology is highly desirable in thermoelectric materials, because the surface roughness of different length scales might result in efficient phonon scattering, reducing the thermal conductivity.

Among the various synthesis methods developed to produce monocrystalline $\mathrm{ZnO} \mathrm{NWs}$,

(Received May 23, 2010; accepted January 17, 2011;

published online February 25, 2011) electrochemical deposition is very attractive, as it allows control of the dimensions and density of $\mathrm{ZnO}$ NWs in an array. Combining electrodeposition with wet etching or colloidal templating (i.e., sphere lithography) enables formation of $\mathrm{ZnO}$ nanotubes (NTs) or 3D hierarchically organized $\mathrm{ZnO} \mathrm{NW}$ (urchin-like) structures with larger aspect ratio than NWs deposited on a flat surface, respectively. This paper summarizes the synthesis, and electrical and optical properties of such $1 \mathrm{D}$ and $3 \mathrm{D} \mathrm{ZnO}$ nanostructures.

\section{EXPERIMENTAL PROCEDURES}

Electrodeposition of $\mathrm{ZnO} \mathrm{NWs}$ was performed in a three-electrode electrochemical cell, using the method based on the reduction of molecular oxygen 
$\left(\mathrm{O}_{2}\right){ }^{1}$ The working electrode (cathode) was made of a $\mathrm{SnO}_{2}: \mathrm{F}$ transparent conducting oxide (TCO) substrate [in some cases covered with a sprayed buffer layer of $\mathrm{ZnO}\left(\mathrm{ZnO}_{\mathrm{sp}}\right)$, playing the role of a seed layer or/and a hole blocking layer]. ${ }^{2}$ The counter and reference electrodes were a $\mathrm{Pt}$ spiral wire and a saturated calomel electrode (SCE), respectively. The electrolyte was an aqueous solution containing $5 \times 10^{-4} \mathrm{M} \mathrm{ZnCl}_{2}$ and $0.1 \mathrm{M} \mathrm{KCl}$ at $\mathrm{pH} 7$ (in standard conditions). The solution was saturated with $\mathrm{O}_{2}$ (10 min bubbling before and during deposition). Electrodeposition of $\mathrm{ZnO}$ occurred from reduction of $\mathrm{O}_{2}$ in the presence of a zinc precursor. By applying a cathodic potential, hydroxide ions (Eq. 1) were electrochemically generated at the electrode surface, leading to precipitation of $\mathrm{ZnO}$ (Eq. 2).

$$
\mathrm{O}_{2}+2 \mathrm{H}_{2} \mathrm{O}+4 \mathrm{e}^{-} \rightarrow 4 \mathrm{OH}^{-}
$$

and

$$
\mathrm{Zn}^{2+}+2 \mathrm{OH}^{-} \rightarrow \mathrm{ZnO}+\mathrm{H}_{2} \mathrm{O}
$$

The $\mathrm{ZnO}$ NW arrays were electrodeposited at a potential of $-1 \mathrm{~V}$ at $80^{\circ} \mathrm{C}$, using an Autolab PGSTAT-30 potentiostat. Ultrapure water $(18 \mathrm{M} \Omega \mathrm{cm})$ was provided by a Millipore setup. Anhydrous $\mathrm{ZnCl}_{2}$ salt (Fluka, purity $>98.0 \%$ ) was used as the $\mathrm{Zn}^{2+}$ precursor. KCl (Fluka, purity $>99.5 \%$ ) served as a supporting electrolyte, among other roles. ${ }^{3}$ Photoluminescence spectra of the urchin-like $\mathrm{ZnO}$ were measured in air at room temperature using a $\mathrm{N}_{2}$ pulsed laser for optical excitation. Measurements were also performed using a HeCd laser (325 nm) with $10 \mathrm{~mW}$ maximal power. The excitation was almost optically focused, with a typical spot diameter of $1 \mathrm{~mm}$. In addition to photoluminescence, direct transmission with a collimated beam was also investigated. In the optical studies, two kinds of samples were studied: as-prepared, and annealed in air at $450^{\circ} \mathrm{C}$ for $1 \mathrm{~h}$.

\section{RESULTS AND DISCUSSION}

\section{Control of ZnO NW Dimensions}

Arrays of vertically aligned $\mathrm{ZnO}$ NWs with controlled dimensions have been obtained by varying the deposition parameters. ${ }^{2-4}$ Numerous parameters influence the dimensions of the NWs, such as the concentrations of zinc $\left(\left[\mathrm{Zn}^{2+}\right]\right)$ and chloride $\left(\left[\mathrm{Cl}^{-}\right]\right.$) ions, the presence of a $\mathrm{ZnO}_{\mathrm{sp}}$ buffer layer, deposition time (charge density), etc. Initial studies showed that $\mathrm{ZnO}$ buffer layers with controllable grain size can be used to influence the diameter and density of the $\mathrm{ZnO}$ NWs in the array. ${ }^{2}$ We have also found that $\left[\mathrm{Cl}^{-}\right]$plays a major role in $\mathrm{ZnO}$ growth mechanisms. ${ }^{3}$ In this work, the influence of $\left[\mathrm{Zn}^{2+}\right]$ and $\left[\mathrm{Cl}^{-}\right]$on NW dimensions were analyzed using a constant charge density $(Q)$. One set of experiments done by varying $\left[\mathrm{Zn}^{2+}\right]$ showed that the diameter of the NWs increased from $25 \mathrm{~nm}$ to $80 \mathrm{~nm}$ when $\left[\mathrm{ZnCl}_{2}\right]$ increased from $5 \times 10^{-5} \mathrm{M}$ to $1 \times 10^{-3} \mathrm{M}^{4}$

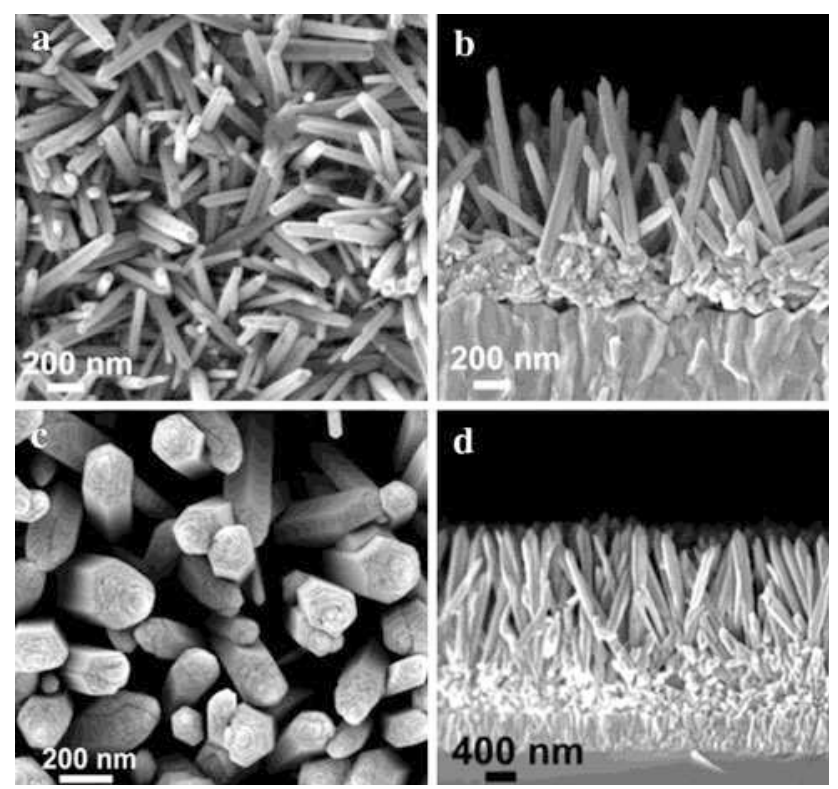

Fig. 1. Plan-view and cross-section SEM images of $\mathrm{ZnO} N W$ arrays. $\left[\mathrm{ZnCl}_{2}\right]=5 \times 10^{-4} \mathrm{M}$. (a, b) $[\mathrm{KCl}]=0.1 \mathrm{M}, Q=20 \mathrm{C} / \mathrm{cm}^{2}$. (c, d) $[\mathrm{KCl}]=3.4 \mathrm{M}, Q=5 \mathrm{C} / \mathrm{cm}^{2}$.

Another set of experiments done by keeping $\left[\mathrm{ZnCl}_{2}\right]$ constant at $5 \times 10^{-4} \mathrm{M}$ and varying [KCl] between $0.05 \mathrm{M}$ and $4 \mathrm{M}$ showed that a jump in nanowire diameter for concentrations higher than $1 \mathrm{M}$ is clearly observed, as well as an increase of the length of the NWs. ${ }^{3}$ This is due to the fact that the rate of $\mathrm{O}_{2}$ reduction (i.e., $\mathrm{OH}^{-}$generation) decreases when $\left[\mathrm{Cl}^{-}\right]$increases. From plan-view scanning electron microscopy (SEM) images, a mean diameter value in the range of $80-100 \mathrm{~nm}$ and up to $300 \mathrm{~nm}$ has been estimated for samples electrodeposited in $[\mathrm{KCl}] \leq 1 \mathrm{M}$ and $[\mathrm{KCl}]>1 \mathrm{M}$, respectively (Fig. 1). ${ }^{3}$ This observation agrees with the role proposed by $\mathrm{Xu}$ et al. that $\mathrm{Cl}^{-}$ions act as a stabilizer of the (0001) $\mathrm{ZnO}$ polar faces. ${ }^{5}$ Two mechanisms of $\mathrm{ZnO}$ NW growth have been predicted. $[\mathrm{KCl}]<1 \mathrm{M}$ hinders diameter growth, favoring longitudinal growth, while when the concentration is lower than $1 \mathrm{M}$ it is diameter growth that is favored ${ }^{3}$ (Fig. 1c, d). Arrays of $\mathrm{ZnO} \mathrm{NWs}$ exhibiting a roughness factor above 70 have been obtained for $[\mathrm{KCl}]=0.1 \mathrm{M}^{4}$

Electrochemical impedance spectroscopy (EIS) was used to investigate the donor density of the $\mathrm{ZnO}$ NW arrays. A Mott-Schottky (MS) model was developed to determine the carrier density in the $\mathrm{ZnO}$ samples. ${ }^{6}$ For the first set of experiments, when $\left[\mathrm{ZnCl}_{2}\right]$ increased from $5 \times 10^{-5} \mathrm{M}$ to $1 \times 10^{-3} \mathrm{M}$, the donor density of the as-deposited NWs decreased from $10^{20} \mathrm{~cm}^{-3}$ to $10^{19} \mathrm{~cm}^{-3}$. The same behavior was observed after annealing, but the values were two orders of magnitude lower. ${ }^{7}$ For the second set of experiments, the donor density of the as-deposited nanowires increased from $7 \times$ $10^{18} \mathrm{~cm}^{-3}$ to $4 \times 10^{20} \mathrm{~cm}^{-3}$, when [KCl] increased from $0.05 \mathrm{M}$ to $4 \mathrm{M}$, respectively. ${ }^{7}$ Annealing in air 


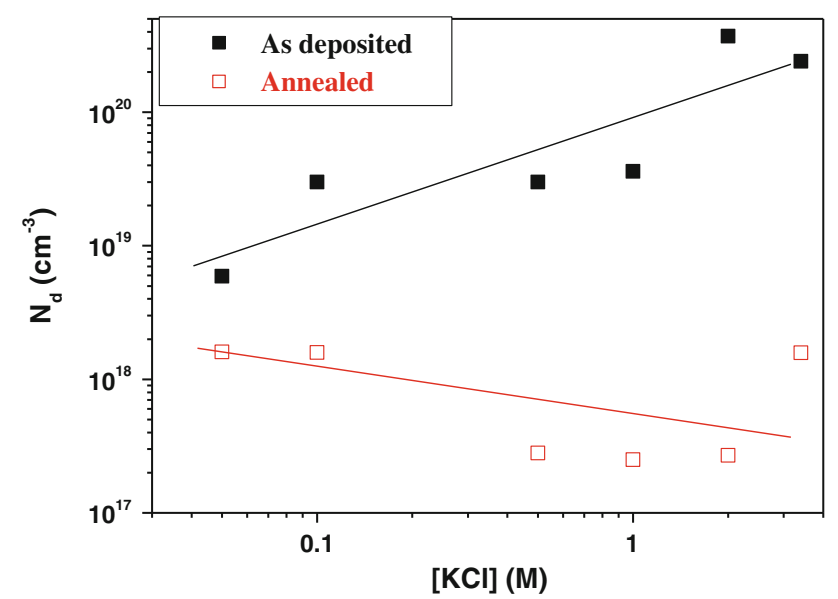

Fig. 2. Donor density of as-deposited and annealed $\mathrm{ZnO}$ NWs as a function of $[\mathrm{KCl}]$, determined from electrochemical impedance spectroscopy.

$\left(1 \mathrm{~h}\right.$ at $\left.450^{\circ} \mathrm{C}\right)$ decreased the donor density to $10^{17} \mathrm{~cm}^{-3}$ to $10^{18} \mathrm{~cm}^{-3}$, weakening the dependence on [KCl] (Fig. 2). The variation of the donor density is related to $\mathrm{Zn}$ interstitials and oxygen vacancies in the $\mathrm{ZnO}$ NWs. $\left[\mathrm{Zn}^{2+}\right]$ and $[\mathrm{KCl}]$ are major parameters that act not only on the dimensions of the NWs but also on the donor density of the $\mathrm{ZnO}$ NWs.

\section{Formation of ZnO NTs}

The method combines the electrochemical deposition of $\mathrm{ZnO} \mathrm{NWs}$ and wet chemical etching of the core of the NWs. ${ }^{8}$ Both steps were done at low temperature $\left(80^{\circ} \mathrm{C}\right)$ in aqueous chloride solution at neutral $\mathrm{pH}$. First, ZnO NTs were obtained starting with electrodeposited $\mathrm{ZnO}$ NWs with relatively low aspect ratio (diameter $\sim 200 \mathrm{~nm}$ and length $\sim 1.5 \mu \mathrm{m}, Q=2.5 \mathrm{C} / \mathrm{cm}^{2}$ ) (Fig. 3a, c). The $\mathrm{ZnO} \mathrm{NWs}$ sample was immersed in $[\mathrm{KCl}]=3.4 \mathrm{M}$ during $2 \mathrm{~h}$ to convert the nanowires into nanotubes. Figure $3 \mathrm{~b}$ shows that the core of the $\mathrm{ZnO}$ NWs is selectively dissolved. Longer ZnO NTs were obtained (Fig. 3e, f) when starting from longer $\mathrm{ZnO} \mathrm{NW}$ s obtained with $Q=10 \mathrm{C} / \mathrm{cm}^{2}$. The dissolution time was $3 \mathrm{~h}$. The selective core dissolution was explained by the ability of $\mathrm{Cl}^{-}$to adsorb preferentially on polar (0001) and $(000 \overline{1}) \mathrm{ZnO}$ surfaces. It was assumed that the (0001) top surface was terminated exclusively by $\mathrm{Zn}^{2+}$ and that $\mathrm{Cl}^{-}$ions preferentially adsorbed on that surface, resulting in the formation of a highly water-soluble zinc chloride complex such as $\mathrm{ZnCl}^{+}$ and in the gradual dissolution of the NW core from the tip towards the bottom. ${ }^{8}$ The nonpolar $(10 \overline{10})$ surfaces parallel to the $c$-axis, being more stable, were not dissolved. Thus, arrays of $\mathrm{ZnO}$ nanotubes with a wall thickness around $35 \mathrm{~nm}$ were obtained (Fig. 3b, e).

\section{Urchin-Like ZnO}

This 3D morphology was obtained by associating the patterning of TCO substrate with a monolayer of polystyrene (PS) spheres and electrochemical deposition of $\mathrm{ZnO}^{9}$ The urchin-like hierarchical structure is composed of vertically oriented $\mathrm{ZnO}$ NWs on PS spheres.

A commercially available suspension of carboxylatemodified PS microspheres $(\Phi \approx 4.3 \mu \mathrm{m}, 4$ wt. $\%$ aqueous dispersion; Duke Scientific, USA) was used as a template. A monolayer of self-assembled PS spheres was deposited on a TCO substrate $\left(\sim 1.5 \mathrm{~cm}^{2}\right)$, using the floating transferring method reported by Zhou et al. ${ }^{10}$ with some modification (Fig. 4a). After
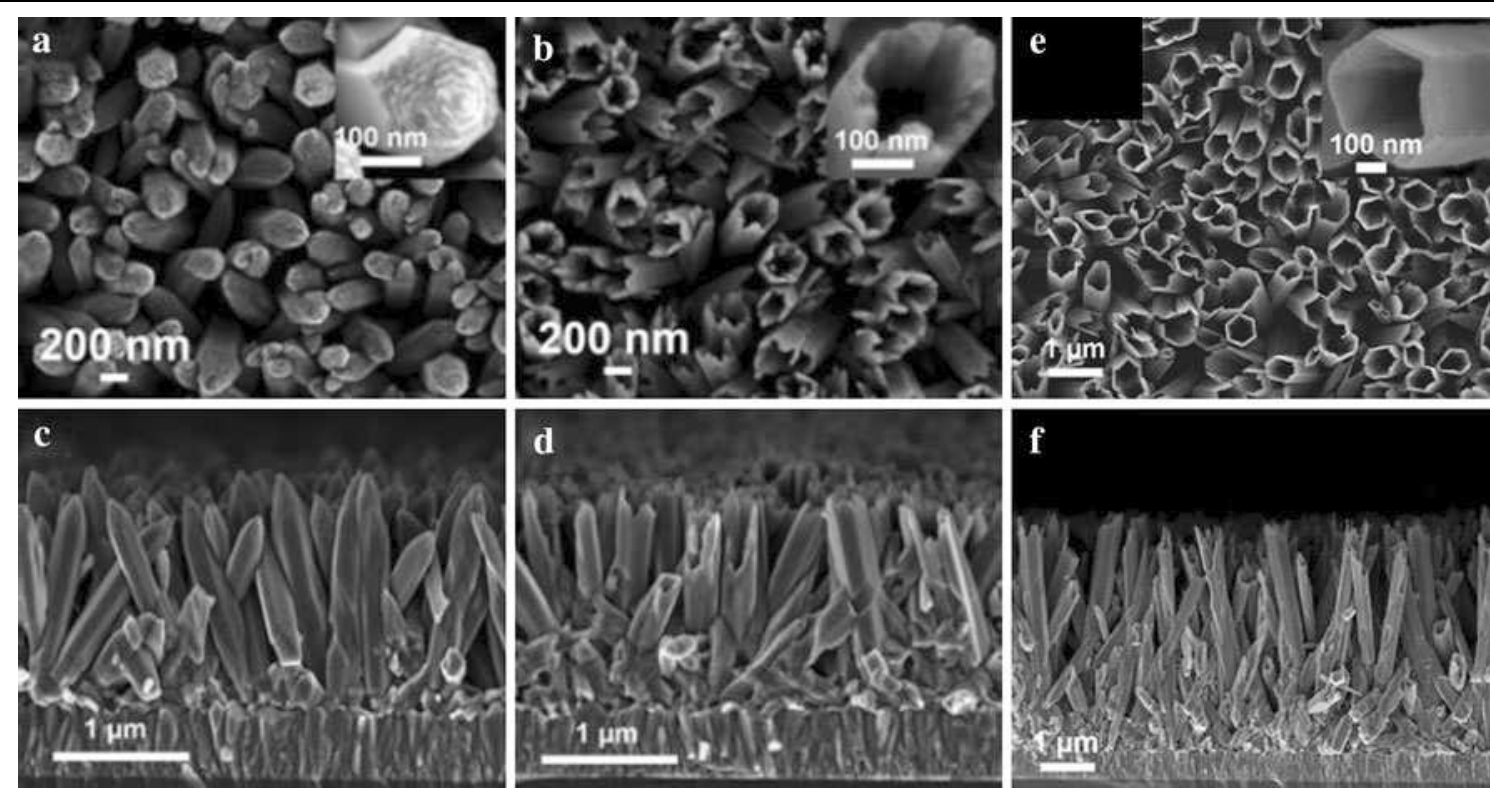

Fig. 3. Plan-view and cross-section SEM images: (a, c) electrodeposited ZnO NW array with $Q=2.5 \mathrm{C} / \mathrm{cm}^{2}$; (b, d) the resulting ZnO NT array after dissolution of the core of the nanowires; (e, f) ZnO NTs obtained from NWs with $Q=10 \mathrm{C} / \mathrm{cm}^{2}$. 

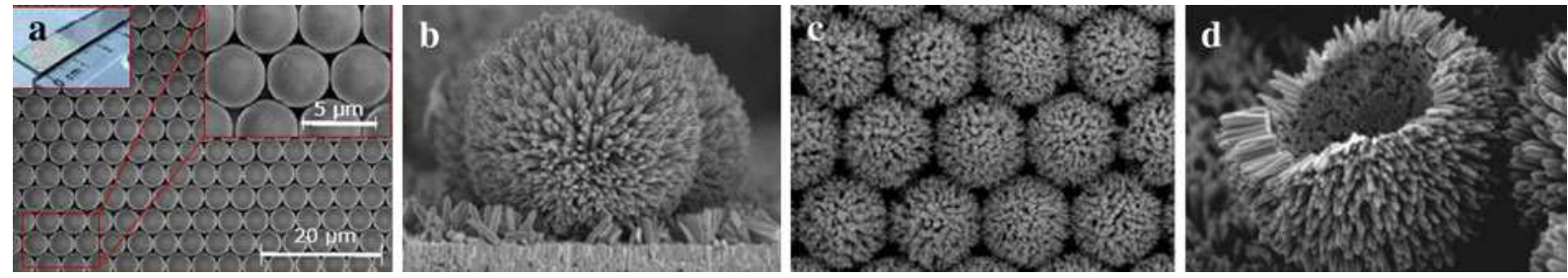

Fig. 4. SEM images. (a) Self-assembled monolayer of PS microspheres on a TCO substrate at low and high magnification (inset) tilted (45 ${ }^{\circ}$ ). The left inset shows a digital image of the same sample. (b) One urchin-like ZnO structure composed of nanowires. (c) Array of urchin-like ZnO structures. (d) One hollow urchin-like $\mathrm{ZnO}$ structure.

drying, the TCO substrate covered with the monolayer was heated in an oven (at $100^{\circ} \mathrm{C}$ for $\left.10 \mathrm{~min}\right)$ to sinter the PS spheres and improve their adherence to the substrate. The left inset to Fig. 4 a shows an optical image of the TCO substrate covered with PS spheres, whose color is perfectly homogeneous, reflecting the presence of only one PS domain (monolayer) on the substrate. The PS spheres display a typical honeycomb structure over the entire TCO surface.

The insulating PS spheres were activated by immersing the TCO/PS sample in $2 \mathrm{M} \mathrm{ZnCl}_{2}$ aqueous solution at room temperature, during $30 \mathrm{~min}$ under low agitation. ${ }^{9}$ This treatment favored adsorption of $\mathrm{Zn}^{2+}$ on the surface of the carboxylatemodified PS spheres through the formation of $\mathrm{COO}^{-}-\mathrm{Zn}^{2+}$ bonds. After rinsing with distilled water, the treated sample was used as a working electrode in a three-electrode electrochemical cell. Electrochemical deposition of $\mathrm{ZnO} \mathrm{NWs}$ on the surface of the PS spheres was performed in $0.1 \mathrm{M}$ $\mathrm{KCl}$ using a charge density of $15 \mathrm{C} / \mathrm{cm}^{2}$. After the electrodeposition, the PS microspheres were dissolved in toluene or burned off in air at $450^{\circ} \mathrm{C}$ during $1 \mathrm{~h}$. The $\mathrm{ZnO}$ NWs were deposited on the surface of each microsphere, whose morphology resembled that of a sea urchin (Fig. 4b). The urchinlike structure was uniform with an average diameter value of $\sim 4.3 \mu \mathrm{m}$ (Fig. $4 \mathrm{c}$ ). After dissolution of the PS spheres, the urchin-like shape was maintained. The cross-section of an urchin-like structure detached from the array and cut through the middle shows that the urchin is hollow with the $\mathrm{ZnO}$ NWs grown vertically on the PS sphere. The average length of the $\mathrm{ZnO} \mathrm{NWs}$ is $\sim 220 \mathrm{~nm}$ (Fig. 4d). The length of the $\mathrm{ZnO}$ NWs can be increased by adjusting the deposition parameters. ${ }^{9}$

The electronic properties of the urchin-like $\mathrm{ZnO}$ were investigated by means of photoluminescence and transmission measurements. As shown in Fig. 5, the as-prepared samples exhibited strong luminescence at room temperature. Several peaks can account for the observed spectra: a strong ultraviolet (UV) emission at $3.225 \mathrm{eV}(385 \mathrm{~nm})$, a smaller peak at $3.0 \mathrm{eV}(413 \mathrm{~nm})$, and a larger band around $2.3 \mathrm{eV}(539 \mathrm{~nm})$, so-called green emission. The luminescence peak at $385 \mathrm{~nm}$ originates from recombination of free excitons at the near-band edge of $\mathrm{ZnO}$ nanowires. ${ }^{11,12}$ The green luminescence for

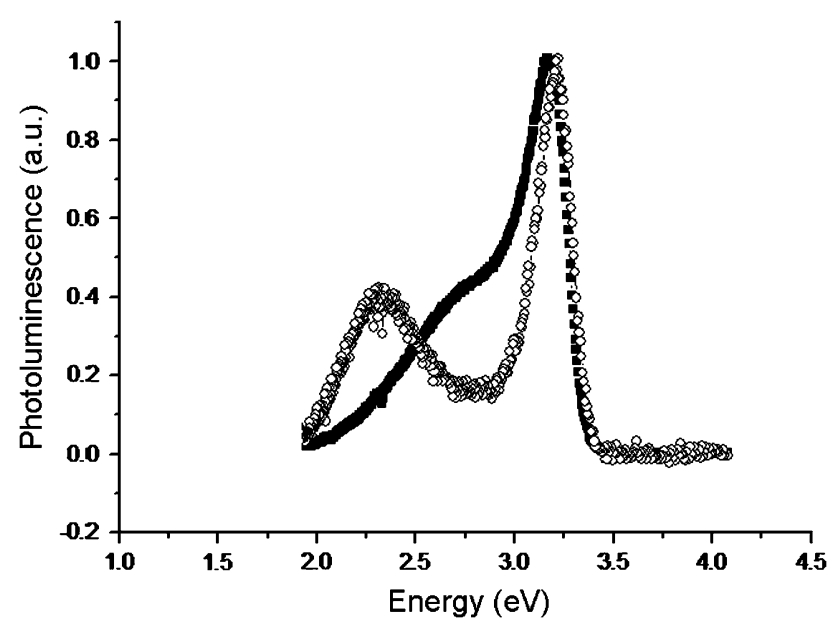

Fig. 5. PL spectra of urchin-like thin films: as prepared (circles) and after annealing (squares). Spectra have been normalized for comparison, with the annealed sample emission being $10 \times$ stronger.

$\mathrm{ZnO} \mathrm{NWs}$ is usually related to the singly ionized oxygen vacancy $\left(V_{\mathrm{O}}\right)$ coming from recombination of a photogenerated hole with the singly ionized charged state of the defect in $\mathrm{ZnO} .{ }^{13}$ As far as the blue-violet emission is concerned, it could be ascribed to $\mathrm{Zn}$ vacancies or in this case to $\mathrm{SnO}_{2}$ used as a conductive layer. The samples were actually observed from the substrate side. Indeed, using a continuous-wave (CW) HeCd laser and exciting from the front side, we observed emission spectra with the three UV, green, and orange emission peaks, the orange emission $(600 \mathrm{~nm}$ to $640 \mathrm{~nm})$ being related to oxygen interstitials. ${ }^{14-16}$ More interestingly, we also investigated annealed samples (solid circles in Fig. 5). In this case, a sharp and much stronger $(10 \times)$ blue-UV emission was observed, confirming the origin of the oxygenrelated defect emission. The improvement of sample quality via thermal annealing was further confirmed by optical transmission measurements, as shown in Fig. 6. Two interesting features can be observed when comparing the as-prepared and annealed samples. The latter shows a more pronounced deep at $376 \mathrm{~nm}$, a smaller transmittance below the band gap, and a higher transmittance above. As for the photoluminescence (PL) results, this behavior is attributed to a decrease of defects in the $\mathrm{ZnO}$ NWs. Although not shown, the PL was 


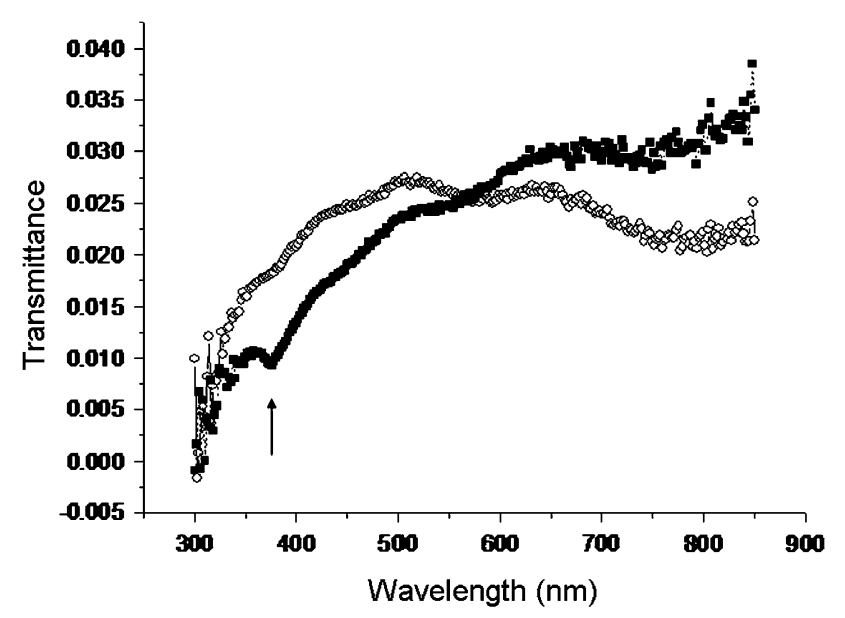

Fig. 6. Direct transmission of urchin-like thin films: as prepared (circles) and after annealing (squares). The deep in the transmittance (arrow) is attributed to the $\mathrm{ZnO}$ direct band gap (376 nm).

found to increase linearly as a function of laser power, except for the excitonic emission, which for the as-prepared sample saturates, most probably because of energy transfer to the defect states. Such behavior was not observed in the annealed sample, confirming the good quality of the deposit.

\section{CONCLUSIONS}

Arrays of free-standing $\mathrm{ZnO}$ NWs with controlled diameter, length, density, aspect ratio, and electrical emission properties were electrodeposited on conductive substrates, by adjusting various deposition parameters. They were transformed into free-standing ZnO NTs that exhibited larger aspect ratio, by selective dissolution into $\mathrm{KCl}$. The aspect ratio was strongly increased when $\mathrm{ZnO}$ NWs were organized in an urchin-like structure, obtained by combining electrodeposition and polystyrene sphere patterning. All the 1D and 3D morphologies are potentially interesting for thermoelectric applications.

\section{ACKNOWLEDGEMENTS}

This work was partially funded by the CNRS within the Energy Program (ZnONanoSol project), France and SFOE (Swiss Federal Office for Energy) project, Switzerland.

\section{REFERENCES}

1. S. Peulon and D. Lincot, J. Electrochem. Soc. 145, 864 (1998).

2. J. Elias, R. Tena-Zaera, and C. Lévy-Clément, Thin Solid Films 515, 8553 (2007).

3. R. Tena-Zaera, J. Elias, G. Wang, and C. Lévy-Clément, J. Phys. Chem. C 111, 16706 (2007).

4. J. Elias, R. Tena-Zaera, and C. Lévy-Clément, J. Electroanal. Chem. 621, 171 (2008).

5. L. Xu, Y. Guo, Q. Liao, J. Zhang, and D. Xu, J. Phys. Chem. B 109, 13519 (2005).

6. I. Mora-Seró, F. Fabregat-Santiago, B. Denier, J. Bisquert, R. Tena-Zaera, J. Elias, and C. Lévy-Clément, Appl. Phys. Lett. 89, 203117 (2006).

7. R. Tena-Zaera, J. Elias, C. Lévy-Clément, C. Bekeny, T. Voss, I. Mora-Seró, and J. Bisquert, J. Phys. Chem. C 112, 16318 (2008).

8. J. Elias, R. Tena-Zaera, G. Wang, and C. Lévy-Clément, Chem. Mater. 20, 6633 (2008).

9. J. Elias, C. Lévy-Clément, M. Bechelany, J. Michler, G.-Y. Wang, Z. Wang, and L. Philippe, Adv. Mater. 22, 1607 (2010).

10. Q. Zhou, J. Zhao, W. Xu, H. Zhao, Y. Wu, and J. Zheng, J. Phys. Chem. C 112, 2378 (2008).

11. Y. Kong, D.P. Yu, and B. Zhang, Appl. Phys. Lett. 78, 407 (2001).

12. T. Voss, C. Bekeny, J. Gutowski, R. Tena-Zaera, J. Elias, C. Lévy-Clément, I. Mora-Seró, and J. Bisquert, J. Appl. Phys. 106, 054304 (2009).

13. K. Vanheusden, C.H. Seager, W.L. Warren, D.R. Tallant, and J.A. Voigt, Appl. Phys. Lett. 68, 403 (1996).

14. S.A. Studeninkin, N. Golego, and M. Cocivera, J. Appl. Phys. 84, 2287 (1998).

15. X.L. Wu, G.G. Siu, C.L. Fu, and H.C. Ong, Appl. Phys. Lett. 78, $2285(2001)$

16. Y.G. Wang, S.P. Lau, H.W. Lee, S.F. Yu, B.K. Tay, X.H. Zhang, and H.H. Hng, J. Appl. Phys. 94, 354 (2003). 